\title{
BULLDOZERS, BIBLES, AND VERY SHARP KNIVES: THE CHINESE INDEPENDENT DOCUMENTARY SCENE
}

\section{ABÉ MARK NORNES REPORTS FROM THE THRIVING FESTIVALS IN SONGHZUANG AND KUNMING, CHINA}

There are three inevitabilities in Chinese independent documentary: demolition, Christianity, and the slaughter of animals great and small. This is only a slight exaggeration. One tends to watch a given film from here waiting for the appearance of crosses and bulldozers, and when animals are led on-stage one prepares for the worst. All three point to the massive flux Chinese society is undergoing. For example, the country is one astoundingly large construction zone; the bulldozers plough down ancient neighborhoods and displace the neighbors to make way for that modern architectural sheen China shows off to the world. The films' Christians, usually from the hinterlands, are locked in constant negotiation with bureaucrats over ways of life (and thus over souls as well); filmmakers deploy their crosses as signs of hope. And as for the sacrifice of animals, this violence aimed at everything from oxen to sparrows points to the matter-of-fact brutality of life in the margins of modernity.

This is a China one will not find on television, and that is precisely the point. A truly independent documentary movement has taken that familiar waveform marked by explosive growth, newness everywhere, and exhilaration over innovative moviemaking and ways of viewing. Twenty-five years ago, I saw my first Chinese documentary, a mind-numbing propaganda piece on irrigation projected in a dreary movie palace in Shanghai. This is the kind of cinema-along with its broadcast television analogue - that the new documentary rebels against.

Most independent films utilize a variation of direct cinema originally learned from Fredrick Wiseman. The other name regularly dropped is Japan's Ogawa Shinsuke, whose long-term study of oppressed peasants informs documentaries about land expropriation protests. The Chinese discovered Ogawa at the Yamagata International Documentary

Film Quarterly, Vol. 63, No. 1, pps 00-00, ISSN 0015-1386, electronic ISSN 1533-8630. ๑ 2009 by the Regents of the University of California. All rights reserved. Please direct all requests for permission to photocopy or reproduce article content through the University of California Press's Rights and Permissions website, hitp://Www.ucpressjournals.com/reprintinfo.asp. DOI: 10.1525/FQ.2009.63.1.00
Film Festival, when successive waves of directors visited in the 1990s. I was working as a programmer at Yamagata throughout this period, and we marveled as the Chinese contingent at the festival grew and grew. Their films increased in number and quality every year until directors like Wang Bing, Feng Yan, and Li Yifan began taking the top prizes at the festival. Since 2000, this energetic growth has taken the proportions of a movement.

A complex of factors has made this development possible, starting with technology. The indies emerged in the late 1980s with the price drop in video camcorders, but it was DV that made all the difference. High-quality capture came into the price range of a rising middle class that could afford cameras and a computer. The camcorders and non-linear editing software automated things to the point that anyone could make movies; most of the filmmakers are poets, painters, novelists, and still photographers, and they shoot without light packages or crews. Using a fairly unprocessed version of direct cinema, they address the spectrum of life the government usually stakes off as taboo: prostitution, bureaucratic corruption, rural protests against land expropriation, the impoverished elderly and mentally handicapped, a compromised education system, religious fervor, homosexuality, and just sexuality period.

Needless to say, this doesn't square with one's image of Chinese image culture. However, these kinds of transformations in style and subject matter should come as no surprise to those familiar with the history of documentary. Filmmakers take every inch they can get. It's the reception context that is truly extraordinary. And the situation can be encapsulated in the example of two festivals: the Yunnan Multicultural Visual Festival (or Yunfest, as it is known) and the China Documentary Film Festival in Songzhuang.

The documentary scene hatched in cafés and universitybased cine-clubs, and after the turn of the century a wide variety of festivals cropped up across the country in cities like 


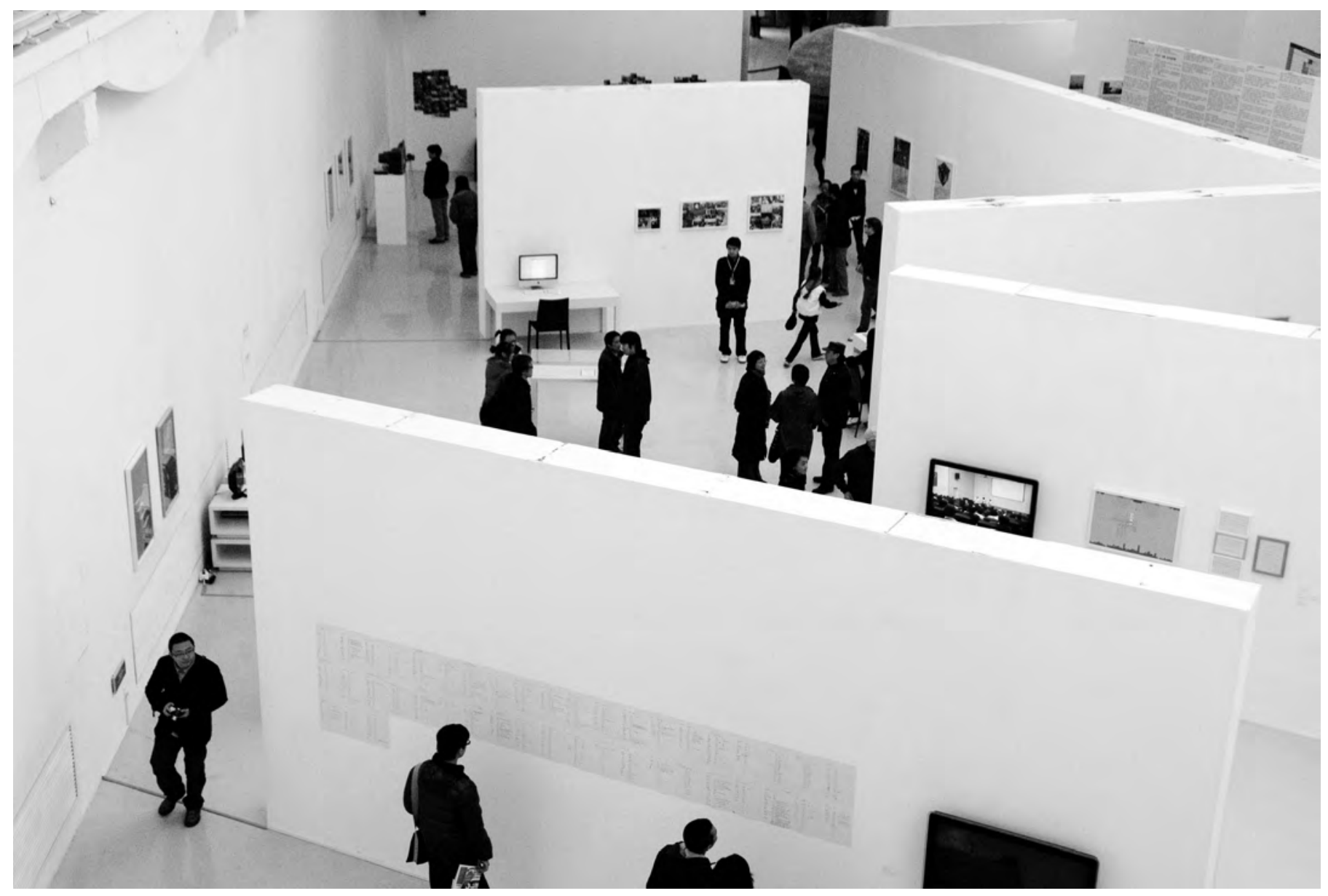

Inaugural film exhibit, Iberia Center for Contemporary Art, Beijing

Photo: Xueyin. Courtesy of CIFA.

Shanghai and Nanjing. There is a single "international festival" in Guangzhou, but as an officially recognized event it is fatally compromised in the eyes of the independents (none of their work could ever pass the censorship Guangzhou entrants must submit to). Yunfest and Songzhuang have achieved their positions of prestige through their uncompromising commitment to independence.

This also makes them thoroughly national affairs. Where the international festival is an interface of the local and global, these events are firmly planted at the heterogeneous nexus of the national. The catalogues are bilingual, but foreign subtitles are often squeezed out by the Chinese subs made necessary by dialects. Interpretation for Q\&A sessions is generally the whispering-of-friends variety. And while the films testify to China's astounding cultural and linguistic differences, Hong Kong and the Chinese diaspora are all but excluded from the films and their discussions. There is a lot of navel-gazing here-granted, the concentration is wholly on poking at the dirt inside. This sense of the documentary world being hermetically sealed by the national border is part of what makes today's scene so fascinating. No doubt it will completely transform in the coming years.

The heterogeneity of the national space is particularly palpable at the biennial Yunfest, which just finished its fourth edition in March 2009. Located in Kunming, far from the bustle of the capital, this friendly and relaxed festival is run, curiously enough, by scholars from the Yunnan Academy of Social Sciences, with sponsorship from NGOs like the Ford Foundation, Toyota Foundation, and Oxfam. It's basically a do-it-yourself affair held in the prefectural library. That one can run one of the most important festivals in the country with projectors placed on tables says a lot about the heady flux of the present moment.

Yunfest is split between a competition and a program on "community video." The organizers are visual anthropologists by trade and seem ambivalent about holding a competition. However, it does perform the usual functions: call attention to the festival, direct cash to worthy (and quite poor) filmmakers, push future production in interesting directions, and introduce key foreign film people to the local documen- 
tary scene by making them jurors. Indeed, this is how I came to write this article.

The competition also provides the occasion for controversy, without which no film festival is complete. This year's object of debate was Xu Tong's Wheat Harvest, China's first prostitution documentary. It is a remarkably intimate portrait of a Beijing prostitute, who sends money home for her loving father's cancer treatments. Uproar greeted the director's revelation that the main character did not know that her life would end up projected in film festivals. A petition circulated to pull it from the competition, and the programmers made space for a four-hour discussion between $\mathrm{Xu}$ and his critics. The jury still gave it a prize. Truth be told, it is unclear that any of the subjects in the competition films realize they are being seen on the international film-festival circuit. The scene here is too fluid and ad hoc, not to mention heroically renegade, to pay attention to such details. This, too, will soon change.

The other major section of Yunfest is the "community video" program, or what would usually be referred to as indigenous or First Nations documentary. This is how Yunfest started out; the visual anthropologists were running a variety of village projects and wanted a public forum for their work. This year's Yunfest featured their own Yunnan-Vietnam Community-Based Visual Education and Communication Project, Wu Wenguang's China Villager Documentary Project and a handful of other NGO-sponsored organizations. Not surprisingly, these nonprofessional villagers use video for everything everybody else does: home movies, the preservation of ephemeral cultural practices, activism, and weddings. All of these projects are experiments: show villagers how to use a camera and edit - and then see what happens. However, several villagers revealed that they had purchased their own cheap, Chinese-made camcorders, indicating that this "lab work" will soon become a normalized documentary culture in rural China.

What fascinates is the positioning of community video in Yunfest. It is by far the largest program, running day and night in one venue. Its well-attended discussion was fully eight hours in length. The villagers were hardly marginalized, as is typical at other film festivals. Aside from the visibility of their colorful costumes, they had their own party with lots of music and dancing from Yunnan's many ethnic minorities. They also provided entertainment for the opening and closing ceremonies. Curiously, the Tibetan filmmakers played background music for the award presentations, and decorated each winner with silk scarves. After it was over and the most of the audience had left, they just couldn't stop playing and those that remained to chat enjoyed an impromptu Tibetan dance jam. Yunfest managed all this, despite the competition, without a whiff of tokenism.

Amid this celebratory and cheerful atmosphere, there is also a sharp edge to the proceedings. Some of the community video filmmakers use their cameras to protest everything from environmental degradation to the impact of tourism to official corruption. And nearly every competition film would make government authorities cringe.

It's no wonder that weeks before the 2007 Yunfest, the government, in the words of festival director Yi Secheng, "suggested we 'postpone' Yunfest until a later date, but they gave no indication for when that later date might come." After some scrambling, they told their guests to come after all, transplanting the festival to the picturesque mountain town of Dali. Yunfest had not asked for permission to exist, nor had it submitted any films for inspection or censorship. Thus, it was clear that the government was tracking the entry films making their way to Kunming. More than one programmer and filmmaker in China told me the same thing: "They know everything." However, this year's festival went off without any visible hitch, although one of the organizers was called in several times to defend the event. Obviously, he did a convincing job of it.

The China Documentary Film Festival in Songzhuang has also had run-ins with authorities. It was shut down in 2007. Like Yunfest, they simply regrouped and quietly moved to an unobtrusive location. During the recent festivals, they had visits by plainclothes policemen, who apparently got bored and disappeared mid-week. Independent documentary is playing a cat-and-mouse game with the government. The latter has opened up a measured free space, the limits of which are constantly tested by filmmakers and festivals alike. Here is a good example illustrating how it works. Anything called a "film festival" in China falls under the bureaucracy overseeing cinema - as in celluloid - and must ask authorities for permission to organize, and then submit to full censorship proceedings. But Yunfest is an "image exhibition" (ying xiang zhan) and Songzhuang is an "exchange week" (jiao liu zhou) so by virtue of verbiage they fall under a less strict bureaucracy that oversees DVDs. This enables the film authorities to simply look the other way while independent documentarists tackle controversial subjects in novel cinematic styles.

There are still limits, although the Songzhuang organizers are particularly aggressive in pushing them. One night at the 2008 edition, an unusual number of people milled around the theater after the last film. Everyone had the same hushed question: "Is it on?" They soon shuffled back into the theater. The festival director, Zhu Rikun, inspected the audience to 

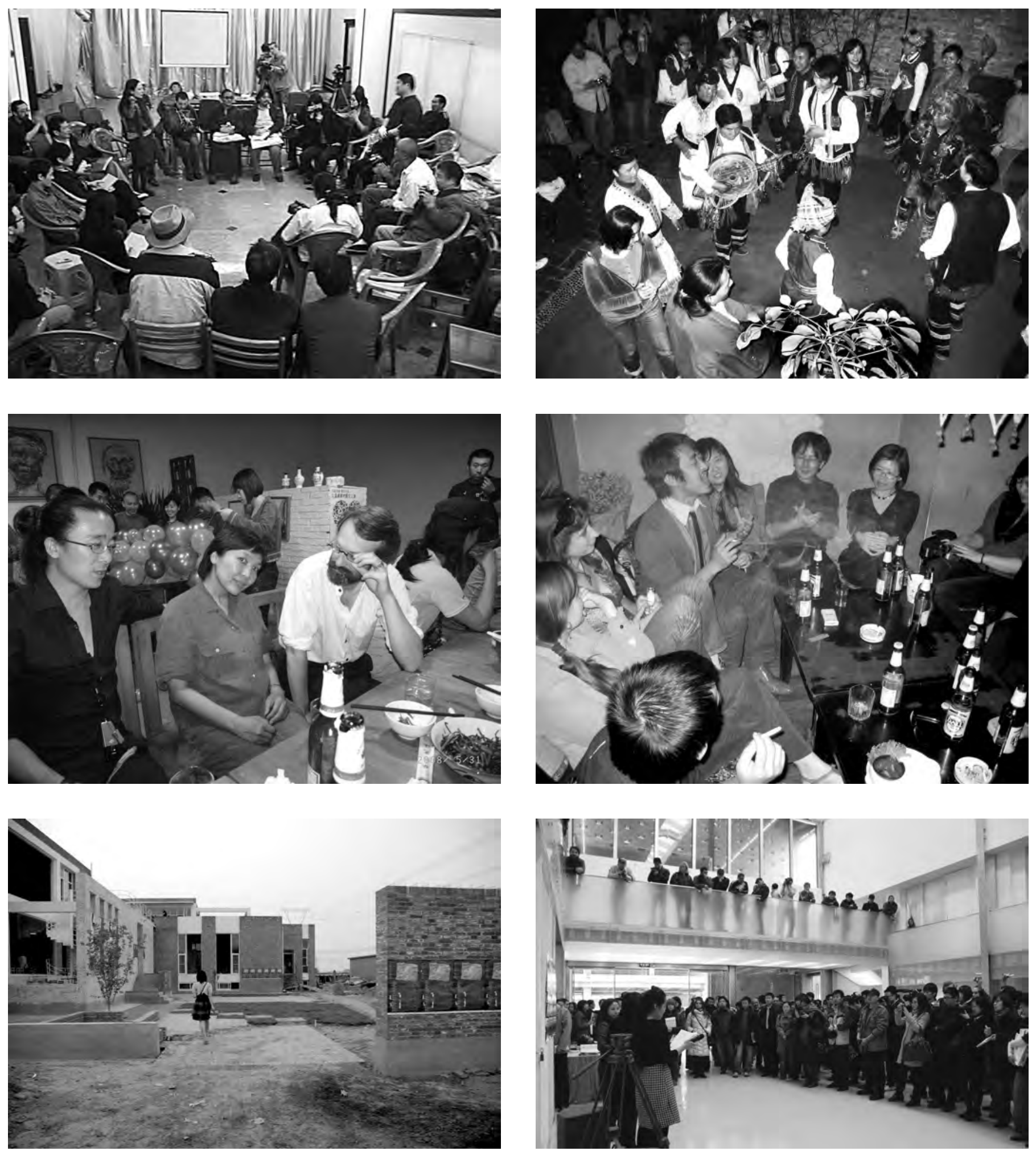

Clockwise from top left: Yunfest community discussion. Yunfest party with ethnic dancers. Yunfest director Yi Secheng sings at an evening party. Iberia film exhibit opening. Construction at Songzhuang. Songzhuang dinner, from left: Zhao Liang, Fujioka Asako, Abé Mark Nornes.

Top two: Abé Mark Nornes. Middle left: Hatano Yukie. Middle right: Abé Mark Nornes. Bottom left: Hatono Yukie. Bottom right: Xueyin. Courtesy of IIFA. 
ensure only invitees were seated. Then he locked the doors, and showed a film they knew could get them in trouble.

Obviously, the government hardly needs this kind of troublemaking to turn the new wave of contemporary documentary to still water. Film history shows that a key arrest or imprisonment is all it takes to shut down cinematic rabblerousing. For now, however, the Chinese government has opened up a zone for independence and documentary film culture is flourishing.

This kind of film culture still requires infrastructure and that in turn demands capital. In one sense the festivals and cine-clubs are working in the place of an as-to-be-created distribution system. And the festivals play the important role of a networking space to share work, build reputations, and spread the word about new films. At the same time, anyone can show a video in a café, but festivals are very expensive affairs. Yunfest is dependent on the largess of NGOs for its existence. The example of the China Documentary Film Festival, however, is far more unconventional and emblematic of the massive changes China has undergone since the turn of the century.

Songzhuang's host is Li Xianting's Film Fund. Li is a famous art critic best known for his unflagging support of modernist artists in the 1980s and 90s. His stamp of approval gave institutional credibility and cultural capital to the generation of artists that is now the object of breathtaking speculation on the international art market. Many of these artists were living near Beijing's Summer Palace, in a colony that was demolished in anticipation of the Olympics. Li, with the blessing of his farmer neighbors, issued an invitation to move to his hometown of Songzhuang. Incredibly, the artists moved en masse to this small village just outside of Beijing (just far enough from the center to relax the grip of the state on artists and filmmakers and programmers).

Thus, the 2008 China Documentary Film Festival was held in one enormous, dusty construction site - a surreal mirror image of all the demolition rendered in the competition films. Everywhere one looked were the half-finished, splendid homes and studios of artists, now fabulously wealthy thanks to the likes of Sotheby's. The main drag was filled with new galleries. Every restaurant in town is decorated with stunning paintings. The festival's spanking-new venue was littered with plates of cut pineapple, which we were assured would absorb the dizzying fumes of wet paint.

As part of their appreciation for the nurturing of $\mathrm{Li}$ Xianting, these same wealthy artists have supported his film fund and its festival. The studio itself is housed in Li's old home, a compound (also under construction) with theater, editing suites outfitted with Mac workstations, a video library, and guest house. In a corner of director Zhu Rikun's office stands a statue by Yue Minjun that is surely worth more than the entire complex. This is where Zhu presides over the China Documentary Film Festival and the Beijing Independent Film Festival. The festivals are held in a cavernous new art museum and a movie theater that, naturally, sports an art gallery like every other building in town.

Songzhuang is just as intimate as Yunfest but, perhaps because of its proximity to the seat of government, it feels far more intense. Here the competition is clearly the center of attention. There is the sense-not least because of the omnipresent dust, clanging, and smell of wet paint-that something utterly new is under construction here ... here in Songzhuang and here in China itself. And the films bear this out.

At the very same time, I cannot help feeling that what's exciting about contemporary documentary in China is coming to a close, that the wave is just now peaking. Consider Iberia, a massive gallery in the heart of 798 Art Zone. This is the expansive munitions factory turned artist colony: 158 acres of galleries, auction houses, and artist studios. A businessman who made his fortune in Europe bankrolls Iberia. Its stunning space, once a factory for war, now displays and sells the latest Chinese art. It also employs a film curator, Zhang Yaxuan, who is particularly devoted to the nonfiction form. (She is also a documentary director in her own right with A Disappearance Foretold [2008], a "demolition film" that played at this year's Yunfest.)

This April, Iberia held its inaugural film exhibition, appropriately centering on the six documentary film venues they deem most important. They include Yunfest, Li Xianting's Film Fund, and the China Documentary Film Festival. The others are Fanhall Films, CCD Workstation, and Indie Workshop. Fanhall is a collective of film fans based in Songzhuang that support their own independent theater by advertising design work. CCD Workstation is Wu Wenguang's dance and video collective, which is hosted by a wealthy businessman who loves documentary (and also lives on the premises). Indie Workshop and the closely affiliated Nanjing Film Festival (which is also supported by a rich businessman) have a far more expansive and eclectic conception of documentary thanks to the leadership of Zhang Xianming, a filmmaker, actor, and Beijing Film Academy professor.

Iberia's Inaugural Exhibition ran for three weeks and projected over eighty films in their new theater. While this testifies to the vibrancy of contemporary documentary, it also signals its institutionalization and the formation of a canon. Indeed, the other significant activity spearheaded by Zhang Yaxuan is the welcome establishment of a documentary film 
archive at Iberia. In other words, Chinese independent documentary has matured to the point of demanding an archive. It is now not simply "contemporary," but also "historical."

Interestingly enough, Yunfest's catalogue featured a significant exchange in essays by Zhang Xianming and Zhang Yaxuan (no relation). The former, something of a trickster, wrote, "Yunfest has only been going on for a few years and people are already calling it a meeting of middle-aged people to exchange their films about old people." To this Zhang Yaxuan issued a repost: "This theme is a response to Zhang Xianming's assertion that independent film is destined to die ... My belief is that we are watching Chinese documentary film form its own tradition. Once that tradition is formed, it will have unstoppable power."

Personally, I think both are correct. Chinese documentary is surely unstoppable, but it has also ossified into an academic and increasingly stale (and excessively easy to produce) direct cinema. As a reaction to both Communist agitprop and conventional broadcast television, this form is probably to be expected. However, like any New Wave or cohesive movement in the history of film, the wave will break. The movement will sputter. This is the only rule of cinema that cannot be broken.

The most cogent sign of the beginning of the end appeared in the form of a protest letter broadcast globally via the Internet in fall 2008. Signed by thirteen filmmakers, it condemned the New York distributor Reel China. This is essentially the concerted and well-meaning work of a New York fan of Chinese independent documentary (with the collaboration of local academics). The international exposure they facilitated across North American universities electrified audiences and sparked a deep interest to learn more (it seems every modern Chinese Studies scholar has an essay, dissertation, or book in the pipeline).

Ironically, Reel China so deeply identified with the movement's rambunctious anything-goes attitude that they apparently accomplished their good work without bothering to clear rights. In many cases, they even failed to inform filmmakers that their work was being distributed!

The signers of the protest were not calling for back payments or declaring their intention to sue. However, they were demanding contractual relationships, hinting at a sea change about to take place. Reel China was operating in the same renegade style as the director of Wheat Harvest. It is this freewheeling, no-holds-barred approach to documentary-and to film festival programming and viewing - that has made contemporary Chinese documentary so utterly fascinating. But the filmmakers are newly professionalizing. They are initiating foreign financing deals and hope dearly for foreign

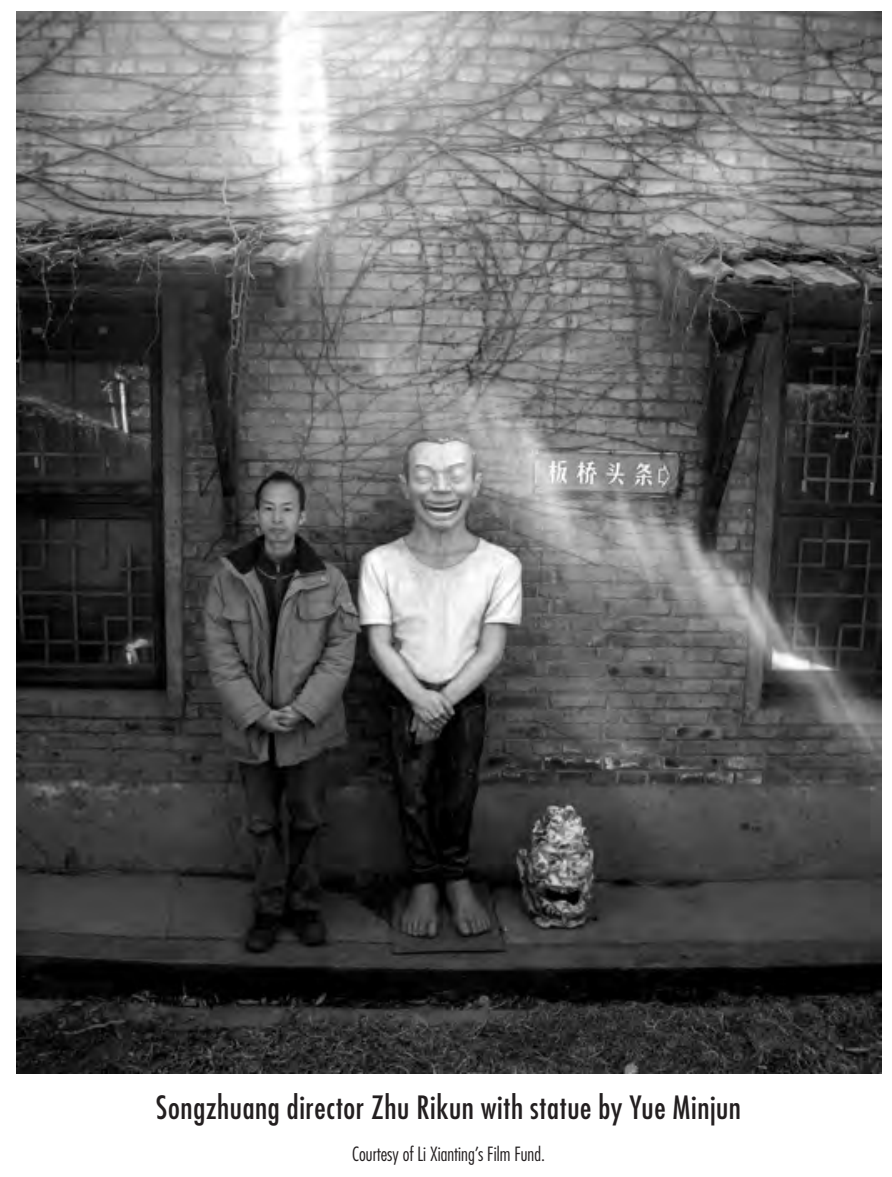

distribution, or better yet broadcast. They are getting older, getting married, and having children. Income is more of a priority. At the same time, the films are swiftly becoming more polished, raising the bar and hinting at an impending end to this ad hoc, do-it-yourself ethos. And when the government's free zone becomes official, as it most certainly will, a formal distribution network will relieve the rich artists and businessmen of the responsibility of connecting filmmakers to audiences.

Having tired of their conservative devotion to direct cinema, not to mention roughshod camerawork and sound for otherwise amazing films, I look forward to something new. Naturally, this imminent end will not be a death, but rather a wondrous transformation.

ABÉ MARK NORNES teaches at University of Michigan and is a former coordinator at the Yamagata International Documentary Film Festival.

ABSTRACT A report on the state of independent documentary filmmaking in China in 2009, covering in particular the Yunnan Multicultural Visual Festival (or Yunfest, as it is known) in Kunming and the China Documentary Film Festival in Songzhuang. A variety of factors have converged to make an anti-authoritarian documentary movement possible, but it may be ending as directors become professionalized.

KEYWORDS Chinese cinema, documentary, film festivals, censorship, Yunfest 